\title{
Em defesa da sociedade: \\ a invenção dos cuidados paliativos \\ e a produção de subjetividades*
}

\author{
IN DEFENSE OF SOCIETY: THE INVENTION OF PALLIATIVE CARE AND \\ THE PRODUCTION OF SUBJECTIVITIES
}

\section{EN DEFENSA DE LA SOCIEDAD: LA INVENCIÓN DE LOS CUIDADOS PALIATIVOS Y LA PRODUCCIÓN DE SUBJETIVIDADES}

\author{
Karen Schein da Silva1 , Maria Henriqueta Luce Kruse ${ }^{2}$
}

\section{RESUMO}

O artigo é uma reflexão teórica que faz parte de um estudo denominado Em Defesa da Sociedade: a invenção dos Cuidados Paliativos. Para articular tal discussão, utilizamos o manual de Cuidados Paliativos, publicado no ano de 2007 pela Organização Mundial da Saúde (OMS), entendendo-o como parte de um artefato capaz de produzir subjetividades e governar condutas. Nesse sentido, pretendemos descobrir como os discursos sobre os Cuidados Paliativos se articulam e efetuam a invenção de uma nova disciplina que funcionaria como uma estratégia biopolítica para defender a sociedade. A partir da análise textual do discurso instituído pelo manual, com o auxílio do referencial dos Estudos Culturais e sob a inspiração dos escritos de Michel Foucault, articulamos uma das possíveis leituras deste guia. Desta maneira observamos a (re)organização e a (re)invenção de uma disciplina que investe na subjetividade dos indivíduos constituindo aparatos de verdade que regulam e governam a população.

\section{DESCRITORES}

Cuidados paliativos

Política de Saúde

Governo

Enfermagem

\begin{abstract}
This article is a theoretical reflection that is part of a study named Em Defesa da Sociedade: a invenção dos Cuidados Paliativos (In Defense of Society: the invention of Palliative Care). In order to articulate this discussion, we used the 2007edition of the Palliative Care Manual published by the World Health Organization (WHO), as we understand it is part of a body of work capable of producing subjectivities and ruling conduct. In this sense, we intend to understand how the discourses on palliative care are associated and promote the invention of a new subject that would work as a biopolitical strategy in order to defend society. Based on the textual analysis of the discourse presented in the manual, with the help of the Cultural Studies framework and inspired by the works of Michel Foucault, we present one of the possible meanings derived from the readings of the WHO Guide. Thus, we observe the (re)organization and (re)invention of a subject that invests in the subjectivity of individuals and constitutes an actual framework that regulates and rules the population.
\end{abstract}

\section{DESCRIPTORS \\ Palliative care \\ Health Policy \\ Government \\ Nursing}

\section{RESUMEN}

Reflexión teórica que forma parte de un estudio denominado En Defensa de la Sociedad: la invención de los Cuidados Paliativos. Para articular la discusión, utilizamos el manual de Cuidados Paliativos, publicado en 2007 por la Organización Mundial de la Salud (OMS), entendiéndolo como parte de un artefacto capaz de producir subjetividades y gobernar conductas. En tal sentido, pretendemos conocer el modo en el que los discursos sobre Cuidados Paliativos se articulan y generan la invención de una nueva disciplina que funciona como estrategia biopolitica para la defensa social. A partir del análisis textual del discurso instituido por el manual, con ayuda del referencial teórico de Estudios Culturales y bajo inspiración de escritos de Michel Foucault, articulamos una posible lectura de la guía. Así, observamos la (re)organización y la (re) invención de una disciplina que invierten en la subjetividad de los individuos, constituyendo aparatos de verdad que regulan y gobiernan la población.

\section{DESCRIPTORES \\ Cuidados paliativos \\ Política de Salud \\ Gobierno \\ Enfermería}

\footnotetext{
* Extraído "Em defesa da sociedade: a invenção dos Cuidados Paliativos, Programa de Pós-Graduação em Enfermagem da Universidade Federal do Rio Grande do Sul, 2010. ${ }^{1}$ Mestre em Enfermagem. Enfermeira do Hospital de Clínicas de Porto Alegre. Porto Alegre, RS, Brasil. karen.schein@gmail.com ${ }^{2}$ Doutora em
} Educação. Professora Associada da Escola de Enfermagem da Universidade Federal do Rio Grande do Sul. Porto Alegre, RS, Brasil. kruse@uol.com.br 


\section{O NASCIMENTO DA BIOPOLÍTICA}

Do que precisamos nos defender? Ou melhor, do que temos medo? Medo é o nome que damos à nossa incerteza: nossa ignorância da ameaça e do que deve ser feito $^{(1)}$. Acreditamos que perguntar, simplesmente, do que temos medo não justificaria esse trabalho; é preciso quem sabe perguntar: o que nos ameaça como espécie, nossa existência? A morte, além de nos causar medo, é, também, uma ameaça à vida. Não é do medo da morte que nos defendemos, mas da ameaça de morrermos. Poderíamos ainda perguntar: de onde vem a questão da invenção? Geralmente, a necessidade de invenção surge de um mal-estar que possa estar estabelecido. É a partir desse desconforto, da necessidade de alternativas, que conseguimos extrair a força que vai mobilizar e viabilizar a invenção de alguma coisa. Dessa maneira, para percebermos como uma invenção se apresenta para a sociedade é preciso salientar que, previamente, foram necessárias pequenas invenções. Assim, em um determinado momento, essas invenções menores fundem-se e formam outro objeto, aparentemente mais acabado, ao qual se atribui um nome e um pseudo dono. Para que essa invenção seja efetuada, ela precisa adquirir um valor, um status, difundir-se, ser socialmente aceita, abrindo precedentes para subjetividades e impondo novas regras ao jogo do funcionamento social(2).

Quando lemos alguma literatura tida como científica, logo procuramos saber: quem tem o direito de proferir aquelas palavras? Quem inventou aquilo? Os princípios de autoria funcionam como controle e registro das verdades produzidas e conferem poderes àqueles que proferem determinados discursos ${ }^{(3)}$. Nesse sentido, poderíamos perguntar quem inventou os Cuidados Paliativos? Mas o que pretendemos fazer não é responder a essa questão, mas olhar para os Cuidados Paliativos como um corpo de conhecimentos que surge como uma alternativa proposta para pensarmos de outro modo a assistência aos pacientes fora de possibilidades terapêuticas de cura. Dessa maneira, nosso objetivo é conhecer como os discursos sobre os Cuidados Paliativos - veiculados pelo manual de Cuidados Paliativos, publicado no ano de 2007 pela Organização Mundial da Saúde (OMS) - se articulam e efetuam a invenção de uma nova disciplina, produzindo outra racionalidade, construindo aparatos de verdade, que subjetivam e governam cuidadores, pacientes, familiares, gestores e profissionais de saúde. Assim, estudar a formação discursiva dos Cuidados Paliativos, no manual da OMS, permite-nos observar a maneira como esse saber circula e como captura os sujeitos configurando o que poderíamos chamar de uma invenção da modernidade.

\section{A TEORIA E A INSTITUIÇÃO DE UM SABER}

Ao investigar as metáforas que envolvem o câncer nos deparamos com as concepções dessa doença como um invasor cruel e secreto, intratável, implacável, que age devagar, de forma traiçoeira. Mesmo que nem sempre o câncer degenere o corpo, cause dor ou provoque a morte, esse modo de caracterizar a doença é bastante difundido. Assim, a equação que iguala câncer a morte é, ainda, bastante prevalente ${ }^{(4)}$.

Se compreendermos a morte não apenas como um processo biológico, mas como um processo históricocultural, perceberemos que a maneira como pensamos tal processo está relacionada às formas como determinadas discursividades nos subjetivam. Embora a biologia do nascimento, da juventude, da doença, da maturidade, da velhice e da morte sejam comuns a todos os seres vivos, a morte é um problema apenas para os seres humanos. Isso porque temos consciência de que ela existe e é uma ameaça para a nossa existência. Antigamente, tanto os nascimentos quanto as mortes se caracterizavam por serem fatos mais públicos e sociáveis do que privados, porém ao longo do processo civilizador mudaram os problemas e as formas como os indivíduos passaram a gerenciá-los ${ }^{(5)}$.

Os conhecimentos técnicos e científicos anteriores ao século $\mathrm{XX}$ caracterizavam a Medicina como predominantemente paliativa, voltada para o alívio do sofrimento e para tratamentos que melhorassem a qualidade de $v^{1} a^{(6)}$. $O$ desenvolvimento tecnológico que passou a ocorrer mais intensamente a partir da metade do século passado transformou os indivíduos em consumidores de cuidados de saúde, produzindo determinados jeitos de cuidar que não visavam, apenas, o alívio do sofrimento, mas a cura dos males. Assim, com o uso da tecnologia e o intervencionismo médico dentro das instituições hospitalares, a Medicina se deslumbrou com a possibilidade de prolongar e controlar a vida, adiando a morte ${ }^{(6)}$. As discussões sobre os problemas da morte no ambiente hospitalar ganharam força e tornaram-se mais frequentes a partir do final da década de 90 , do século XX, quando discursos sobre uma nova modalidade assistencial, que surgiu como reação à Medicina tecnicista, passaram a circular compondo um saber que pretenderia colocar a morte sob outro regime de discurso: os Cuidados Paliativos. Começa, então, a ocorrer uma modificação na formação dos enunciados sobre a morte e o morrer e nas formas como eles passam a ser regidos para serem aceitos como verdades, constituindo o corpo de conhecimentos dos Cuidados Paliativos como um outro modo de gerenciar a morte. Essa filosofia assistencial é descrita como tendo 
sua origem no Reino Unido, na década de 60 , a partir da criação do St. Christhopher Hospice, em Londres, pela médica, enfermeira e assistente social Cicely Saunders ${ }^{(6)}$. A criação desse hospice é, geralmente, atrelada ao nascimento dos Cuidados Paliativos.

Com o intuito de organizar um corpo de conhecimentos voltado para uma assistência mais humanizada no período que precede a morte, Saunders teria criado a filosofia hospice, uma proposta terapêutica que não surgiria em substituição à assistência biomédica tecnicista vigente, mas sim em associação a esse modelo(7). Essa ruptura entre a morte moderna e a morte pós-moderna não teria o objetivo de libertar os sujeitos da morte silenciada e ocultada, mas de colocá-la em uma nova ordem de discurso, submetida a outros dispositivos de poder e saber, modificando práticas assistenciais e (re)fabricando sujeitos ${ }^{(8)}$.

\section{A HERMENÊUTICA DA PESQUISA}

A trajetória metodológica determina o caminho a ser percorrido. Por que decidimos buscar certas estradas e não outras? Certamente a escolha do método não é feita ao acaso, mas é uma escolha interessada que fazemos, por acreditar que seguindo determinado caminho conseguiremos desenvolver as reflexões que propomos. Método, neste trabalho é entendido como algo mais maleável, como uma forma de interrogação, como uma das possíveis formas de pensamento e de análise.

Para responder ao nosso objetivo realizamos uma análise textual relacionada ao campo dos Estudos Culturais, especialmente a vertente pós-estruturalista de inspiração foucaultiana. A inspiração foucaultiana envolve admitir que só se pode utilizar esse autor quando o objetivo não for formular conceitos ou atingir verdades pré-existentes e ocultas, aguardando sua descoberta, mas quando objetivamos operar sobre documentos para interrogar o encadeamento de acontecimentos em determinados espaços, atrelados a determinadas histórias ${ }^{(9)}$. As análises textuais contribuem para a compreensão de fenômenos e regras que governam a produção de discursos numa determinada época, mostrando os diferentes significados que estão atrelados na produção de sujeitos. Esse tipo de análise trata os diferentes espaços do mundo contemporâneo como produtores de pedagogias, ou seja, somos constituídos pela televisão, jornais, livros, fotos, manuais etc ${ }^{(10)}$. Portanto realizamos uma hipótese de leitura do manual da World Health Organization sobre Cuidados Paliativos, que faz parte da série Cancer Control: Knowledge into Action: WHO Guide for Effective Programmes ${ }^{(11)}$. Esse manual, publicado em 2007, pode ser encontrado em língua inglesa no sítio da WHO na internet. Para a realização das análises foi necessário traduzir o guia para a língua portuguesa. Tal tradução foi realizada por um bacharel em letras/inglês e validada por uma profissional da área da saúde com conhecimentos no idioma. Como pesquisado- ras e autoras desse estudo, assumimos a responsabilidade das traduções realizadas.

Nesse sentido, propusemos-nos a utilizar os instrumentos disponibilizados pelo referencial para transitar por entre as enunciações do manual realizando uma leitura interessada dos textos, ou seja, (...) trata-se de saber aquilo que podemos aproveitar e aquilo que podemos descartar, deixar passar ou deixar de lado(12). Para tanto, utilizamos algumas ferramentas e teorizações de Michel Foucault as quais viabilizaram essa forma de pensamento e análise.

\section{PRODUZINDO SUBJETIVIDADES}

Se fosse possível analisar a sociedade ocidental utilizando as diferentes tecnologias de poder desenvolvidas ao longo da obra de Foucault, talvez pudéssemos falar de três diferentes tipos de governamentalidades: soberania (que seria uma governamentalidade de justiça), disciplina (que seria uma governamentalidade administrativa) e segurança (que seria uma governamentalidade de governamento) ${ }^{(13)}$. Não podemos compreender esses três tipos de governamentalidades como uma em substituição a outra, mas sim como um triângulo formado por soberania, disciplina e gestão governamental, o qual faz a população aparecer como um dado, um objeto de intervenção(13).

Na sociedade de segurança, molda-se o meio em relação aos acontecimentos, ocorre a regulação dos elementos, normaliza-se, ou seja, observam-se as normalidades para posteriormente produzir a norma. O foco está no coletivo, partimos dele para o individual, e a população passa a ser um dado dependente de um conjunto de variáveis; fala-se em sujeito coletivo. Devemos entender que a segurança é uma certa maneira de acrescentar, de fazer funcionar, além dos mecanismos propriamente de segurança, as velhas estruturas da lei e da disciplina ${ }^{(13)}$. Assim, a governamentalidade, na sociedade de segurança, vai organizando as diferentes tecnologias de poder em sua maquinaria para a preservação da vida, constituindo sujeitos.

A biopolítica do manual de Cuidados Paliativos da OMS pode ser vista como um discurso que tenta determinar e delimitar um campo de saber. Para realizar tal feito, define regulamentos, produz subjetividades, determina certos campos de ações e condutas, (re)inventa esse saber e define posições de sujeitos para pacientes, familiares, profissionais de saúde e outros, governando suas vidas e pretendendo proteger a vida da população. Nesse sentido, o manual estabelece como devem ser formadas as equipes que prestarão assistência aos pacientes em Cuidados $\mathrm{Pa}$ liativos, bem como as ações de cada membro, sugerindo que esses grupos de trabalho devem ser multidisciplinares e que cada disciplina terá seu campo de ações específico, desempenhando determinado papel com ações bem delimitadas. É destacada a importância de as equipes estarem integradas com a comunidade e serem compostas por lí- 
deres comunitários, agentes de saúde, familiares, cuidadores, conselheiros espirituais, voluntários e profissionais de saúde, dentre os quais deverão estar médicos, enfermeiros, psicólogos, assistentes sociais e farmacêuticos. Deste modo, cada membro da equipe ocuparia um espaço específico, de modo que, quando reunidos, formariam a rede necessária para a existência de uma assistência paliativa. Para marcar as diferentes posições de sujeito, a OMS determina as ações dos membros dessa equipe e ensina como ser e o que fazer para ocupar tais posições. Para entendermos como esses enunciados nos subjetivam, constituindo aquilo que somos, podemos observar, por exemplo, a maneira como o manual projeta os sujeitos médicos e os sujeitos enfermeiras, determinando as suas condutas e constituindo-os.

De acordo com o manual, os médicos teriam um papel crucial, pois necessitariam ter conhecimentos suficientes sobre medicina geral, controle da dor e outros sintomas para gerenciar as doenças dos pacientes, o que às vezes os colocaria frente a dilemas no tratamento. Além disso, esses profissionais poderiam ocupar a coordenação das equipes de Cuidados Paliativos, exercendo papel educativo importante ${ }^{(11)}$. Podemos observar tal enunciação no seguinte excerto:

Os médicos exercem um papel crucial nos Cuidados Paliativos interdisciplinares. Devem ser competentes em medicina geral, competentes em controle da dor e outros sintomas. (...) Também podem ser responsáveis pela coordenação das equipes interdisciplinares. Claramente desempenham um papel educativo importante ${ }^{(11)}$.

De acordo com o manual, as enfermeiras seriam as profissionais que ficariam a maior parte do tempo em contato com os pacientes e suas famílias, conhecendo melhor o contexto em que vivem e interferindo no sofrimento quando a doença alcançasse estágios avançados. Para o guia, seria de suma importância que essas profissionais fornecessem cuidados físicos e suporte emocional, atuassem no gerenciamento dos sintomas e na educação dos pacientes e de seus familiares. Além disso, seria de responsabilidade das enfermeiras, quando em atuação na atenção primária, a supervisão e o treinamento de líderes comunitários, cuidadores, familiares e voluntários. Para a OMS, as enfermeiras gerenciariam as equipes quando o quantitativo de médicos fosse insuficiente, mas para tanto necessitariam de treinamentos especializados ${ }^{(13)}$. Podemos observar tal enunciação no trecho abaixo:

A enfermeira é um membro da equipe que, tipicamente, mantém o maior contato com o paciente. Este contato prolongado dá a enfermeira uma oportunidade única de conhecer o paciente e os cuidadores (...), assim como ajudar o paciente a lidar com os efeitos da progressão da doença. A especialização da enfermeira na prestação de cuidados físicos e emocionais para o paciente, no manejo dos sintomas, na educação do paciente e de sua família e na organização do ambiente do paciente para mi- nimizar a perda do controle, é de suma importância para os Cuidados Paliativos. As enfermeiras são capazes de trabalhar de maneira muito próxima ao paciente e seus familiares para fazer os encaminhamentos apropriados para outras disciplinas e serviços de atenção à saúde. Em algumas situações, onde o número de médicos é pequeno as enfermeiras podem liderar a equipe multidisciplinar e serem responsáveis pela prestação de todos os aspectos dos Cuidados Paliativos. Nessas situações, as enfermeiras precisam de treinamento especializado que seja apropriado às circunstâncias econômicas e culturais de onde trabalham ${ }^{(11)}$.

Entendemos que essas características atribuídas ao médico e à enfermeira estão associadas a questões de gênero, à prática profissional e aos significados cultural e historicamente construídos e atribuídos às diferentes profissões. O médico - profissional, na maioria das vezes, representado pelo sexo masculino - emerge como um ser poderoso e com superioridade em relação às profissões tidas como tipicamente femininas, como é o caso da Enfermagem, embora mudanças venham ocorrendo nesses cenários. Ele seria o profissional que teria o poder da cura, do tratamento, da decisão sobre os rumos da vida e da morte do paciente, desqualificando e tornando as práticas de cuidados em saúde, aparentemente subordinadas ao seu comando, configurando uma assimetria de sexo-classe ${ }^{(14)}$. As enfermeiras, que organizaram suas práticas baseadas nas ordens sacras, desempenhariam atividades tidas, na cultura, como naturalmente femininas - como limpeza, cuidado, nutrição, entre outras -, pois essa profissional nasceu associada à figura da mulher-mãe, detentora de um saber tipicamente feminino de práticas de saúde e cuidados que se profissionalizou e estabeleceu relações de trabalho num universo médico-masculino ${ }^{(14-15)}$. Dessa maneira, caberia à enfermeira assumir uma gama de responsabilidades que atendessem às necessidades humanas básicas, inclusive, realizando a cobertura de possíveis deficiências dos demais serviços e profissionais envolvidos na assistência à saúde, respondendo por todos os tipos de situações que se relacionem ao paciente ${ }^{(16)}$. Assim, no excerto extraído do manual, parece haver nas atividades da enfermeira funções que seriam de responsabilidade de outros profissionais. Existiria uma diferenciação entre as atividades privativas do médico e todas as outras, que, quando não realizadas pelos profissionais especialistas, poderiam ser desempenhadas pela enfermeira. Dessa maneira, em uma política direcionada para os cuidados de saúde com foco no conforto do paciente, as enfermeiras tornam-se imprescindíveis, funcionando como o elo que ligaria e articularia os demais profissionais e práticas. Porém é interessante observar que mesmo se tratando de uma disciplina na qual o foco está no Cuidado Paliativo e não no tratamento curativo da doença, essas profissionais ainda aparecem em condições de desigualdades quando comparadas aos médicos, o que, de certa maneira, desqualificaria a sua prática profissional. 
Pode-se destacar que, de modo geral, no currículo das faculdades de Medicina, não encontramos disciplinas que preparem esses profissionais para cargos de gerência, enquanto nas Escolas de Enfermagem essas disciplinas fazem parte da formação profissional, tendo em vista que a enfermeira é preparada para liderar um grupo de profissionais que estará sob a sua supervisão. Podemos observar como essas profissões carregam marcas históricas e culturalmente produzidas, que tem se mantido até hoje, estabelecendo que a enfermeira deva trabalhar subordinada ao médico, como se fosse possível hierarquizar profissões que atuam em planos distintos de ação. Tal fato pode guardar relação com a maneira como a Enfermagem emergiu como profissão, no ambiente hospitalar para assegurar o exame e a vigilância contínua dos pacientes, já que o médico não poderia fazê-lo. Assim podemos observar como a cultura produz posições de sujeitos e reproduz modos de ser médico, ou de ser enfermeira, de ser homem ou de ser mulher que são escritos a partir de uma rede discursiva, tecida e articulada histórica e culturalmente.

A partir de tal enunciado que vai desenhando a enfermeira como sujeito é possível olhar para essa profissional dentro da lógica do poder pastoral proposta por Foucault. O pastorado é introduzido no Ocidente pelo cristianismo como poder individualizador, que seria praticado pelo pastor em relação ao seu rebanho. Assim, a Enfermagem pauta-se nessa tecnologia de poder para desenvolver suas atividades na condução do rebanho (os pacientes). A enfermeira ou pastora seria a responsável por reunir, guiar, conduzir e vigiar o seu rebanho, assegurando sua salvação e sua vida. Ainda caberia à enfermeira ou pastora oferecer uma atenção individual a cada membro do rebanho e velar permanentemente pela vida de todos e de cada um, ajudá-los, melhorar seu destino(17). É produtivo compararmos a enfermeira e suas atividades na prestação dos cuidados em saúde, especialmente as atividades assistenciais propostas pelo manual da OMS, com o poder pastoral, pois vamos percebendo que essa tecnologia de poder transpassa o cotidiano do trabalho da Enfermagem. O pastor deve dar conta não apenas das ovelhas, mas das suas ações e de tudo que Ihes acontece, provendo as necessidades de cada uma sem se descuidar do grupo. O que seria o poder pastoral senão o cotidiano da assistência de Enfermagem, especialmente desta assistência de Enfermagem em Cuidados Paliativos? Desse modo, o manual preconiza que a enfermeira seja a pastora, zele pelo rebanho, governe o meio em que vivem, enfim. Portanto temos que pensar no pastorado como uma forma de governar os seres humanos, ou seja, uma maneira da enfermeira governar os pacientes e familiares, constituindo também suas posições de sujeito, ensinando como devem ser e o que devem fazer dentro dessa disciplina dos Cuidados Paliativos. De acordo com Foucault, poderíamos pensar no pastorado em relação ao rebanho ou, nesse caso, na enfermeira em relação aos pacientes, da seguinte maneira: o tema da vigília é importante. Ele faz ressaltar dois aspectos do devotamento do pastor. (...) Ele presta a atenção em todos, sem perder de vista nenhum deles. Ele é levado a conhecer seu rebanho no conjunto, e em detalhe. Ele deve conhecer não somente a localização das boas pastagens, as leis das estações e a ordem das coisas, mas também as necessidades de cada um em particular ${ }^{(17)}$.

A partir de uma ou de outra posição de sujeito passamos a constituir e a desenhar as demais posições de sujeito que estariam envolvidas no regime discursivo da assistência paliativa proposto pela OMS. Aqui cabe lembrar que sujeitos são constituídos a partir de arranjos discursivos, os quais promovem um processo de identificação, fazendo com que sejam interpelados, subjetivados e constituídos como sujeitos de um determinado tipo. De tal maneira, o discurso dos Cuidados Paliativos, que é sustentado pelo trabalho integrado e multidisciplinar, também é reafirmado pelo guia de Cuidados Paliativos, contribuindo para que, ao pensarmos nesse campo de saber, lembremos da importância de curandeiros, assistentes sociais, psicólogos, farmacêuticos, voluntários (posições de sujeito também definidas pelo manual) e não apenas do médico e da enfermeira. Para governar a população, tornou-se necessário que outros saberes pudessem emergir e se aliar aos saberes já existentes para viabilizar um bom governamento. Parece que na área da saúde as profissões de médico e enfermeira passaram a não ser suficientes, viabilizando o surgimento de outras profissões, outros regimes de discursos que pudessem se ocupar do governo de pacientes e familiares. Deste modo, o exercício do governamento da população pode se dar de forma rizomática, no detalhe, capilarmente, subjetivando e constituindo sujeitos, (re)inventando o regime de verdade dos Cuidados Paliativos.

\section{DO GOVERNAMENTO DO MANUAL}

Nesse estudo objetivamos conhecer como os discursos sobre os Cuidados Paliativos, veiculados pelo manual da OMS, se articulam e (re)inventam uma nova disciplina, produzindo outra racionalidade, construindo aparatos de verdade que nos subjetivam e governam Nesse sentido, o manual de Cuidados Paliativos funcionaria como um sistema de expertise que buscaria educar, governar e subjetivar os personagens envolvidos nesse regime discursivo. As biopolíticas precisam dar conta de todos os fenômenos que perpassem a vida, nada lhes deve escapar, pois elas devem gerir o funcionamento social. Assim, programas e políticas vão sendo arquitetados e executados para promover a regulação da população.

Nossas práticas devem receber a legitimidade do estatuto da ciência para ter credibilidade, prestígio e validade $^{(18)}$, pois a verdade é centrada na forma do discurso científico e nas instituições que o produzem (...) $)^{(19)}$. Nesse sentido, o discurso dos Cuidados Paliativos, ao ser apropriado e sistematizado pela OMS, passa pelo filtro da ciência e adquire legitimidade para regular determinadas práticas
Em defesa da sociedade: a invenção dos cuidados paliativos e a produção de subjetividades Silva KS, Kruse MHL 
na assistência à saúde, minimizando as ansiedades dos indivíduos e suas famílias frente à terminalidade da vida, uma vez que pretenderiam garantir um determinado modo de morrer. $O$ discurso instituído pelo manual pode ser pensado como um regime de verdade que (re)organiza e (re)inventa uma disciplina que investe na subjetividade dos indivíduos, constituindo determinadas posições de sujeito.

\section{REFERÊNCIAS}

1. Bauman Z. Medo líquido. Rio de Janeiro: Jorge Zahar; 2008.

2. Lazzarato M. As revoluções do capitalismo: a política no império. Rio de Janeiro: Civilização Brasileira; 2006.

3. Foucault M. A ordem do discurso: aula inaugural no Collège de France, pronunciada em 2 de dezembro de 1970. 13a ed. São Paulo: Loyola; 2006.

4. Sontag S. Doença como metáfora: AIDS e suas metáforas. São Paulo: Companhia das Letras; 2007.

5. Elias N. A solidão dos moribundos: seguido de envelhecer e morrer. Rio de Janeiro: Jorge Zahar; 2001.

6. Pimenta CAM, Mota DDCF, Cruz DALM. Dor e cuidados paliativos: enfermagem, medicina e psicologia. São Paulo: Manole; 2006.

7. Maciel MGS. A terminalidade da vida e os cuidados paliativos no Brasil: considerações e perspectivas. Prat Hosp [Internet]. 2006 [citado 2007 jun. 10];8(47):46-49.Disponível em: http:// www.praticahospitalar.com.br/pratica\%2047/pdfs/mat\%20 14.pdf

8. Silva KS, Kruse MHL. As sementes dos cuidados paliativos: ordem do discurso de enfermeiras. Rev Gaúcha Enferm. 2009;30(2):183-9.

9. Veiga-Neto A. Foucault e a educação. 2a ed. Belo Horizonte: Autêntica; 2007.

10. Costa MV, Silveira RH, Sommer LH. Estudos culturais, educação e pedagogia. Rev Bras Educ. 2003;(23):36-61.
Portanto nossas análises pretenderam olhar para a forma como os mecanismos de poder impressos em uma cultura atuam constituindo sujeitos e subjetividades, nos ensinando, controlando e governando, modelando nossos corpos e nossas ações, delimitando campos de saber por meio de um discurso que produz efeitos de verdade.

11. World Health Organization (WHO). Cancer control: knowledge into action: WHO Guide for Effective Programmes: Palliative Care [Internet]. Geneva; 2007 [cited 2009 Feb 18]. Available from: http://www.who.int/cancer/media/FINALPalliativeCareModule.pdf

12. Veiga-Neto A, Fischer RMB. Foucault, um diálogo. Educ Real. 2004;29(1):7-25.

13. Foucault M. Segurança, território, população: curso dado no Collège de France (1977-1978). São Paulo: Martins Fontes; 2008.

14. Lopes MJM, Leal SMC. A feminização persistente na qualificação profissional da enfermagem brasileira. Cad Pagu . 2000;(24):105-25. [citado 2007 jun 10].

15. Kruse MHL. Os poderes dos corpos frios: das coisas que se ensinam às enfermeiras. Brasília: ABEn; 2004.

16. Meyer DE. Ao olhar-se no espelho, a enfermeira não tem gostado da imagem que aí vê refletida. Rev Bras Enferm. 1992;45(2/3):176-82.

17. Foucault M. Poder e saber. In: Foucault M. Ditos e escritos IV: estratégia poder saber. $2^{a}$ ed. Rio de Janeiro: Forense Universitária; 2006. p. 223-40.

18. Costa MV. Uma agenda para jovens pesquisadores. In: Costa MV. Caminhos investigativos II: outros modos de pensar e fazer pesquisa em educação. Rio de Janeiro: DP\&A; 2002.

19. Foucault M. Microfísica do poder. 21a ed. Rio de Janeiro: Graal; 2005. 